\title{
Detection with flash gas chromatography electronic nose of the general influences of glutathione, ascorbic acid, tannin and carbon dioxide treatments on the volatile profiles of white wines of feteasca regala
}

\author{
Arina Oana Antoce ${ }^{\mathrm{a}}$ and George Adrian Cojocaru ${ }^{\mathrm{b}}$ \\ University of Agronomic Sciences and Veterinary Medicine of Bucharest, Faculty of Horticulture, Department of Bioengineering of \\ Horti-Viticultural Systems, 59, Mărăşti Ave., Sector 1, 011464 Bucharest, Romania
}

\begin{abstract}
The present work aimed to determine some of the influences of the treatments with glutathione (GSH), ascorbic acid (AA), catechinic tannin (T) and carbon dioxide $\left(\mathrm{CO}_{2}\right)$ during winemaking or bottling on the volatile profiles of white wines of Feteasca Regala. The study is based on the use of a flash gas chromatography electronic nose, which is able to discriminate various clusters of wine samples prepared with various combinations of antioxidants. The treatments that induce enough differences in the volatile profiles of the wine that the electronic nose is able to discriminate are likely to be discriminated also by the consumers. When the electronic nose does not discriminate the clusters of samples with certain treatments it is very likely that those treatments are not sufficient to induce a practically important difference in the aromatic profile of wines. The main detectable influences of the antioxidant treatments are presented and discussed. The treatment of musts with AA $(50 \mathrm{mg} / \mathrm{l})$ clearly influences the volatile profile of the wines, reducing their aromatic complexity. The treatment during bottling with catechinic tannin $(20 \mathrm{mg} / \mathrm{l})$ does not seem to have an important influence of the profile of the wines produced with the addition of AA and or GSH. The addition of carbon dioxide during bottling does not show much influence one year after bottling, but it shows that in the samples most prone to oxidation, a difference is present. The $\mathrm{CO}_{2}$ treated wines belonging to the cluster of wines treated with $40 \mathrm{mg} / \mathrm{l} \mathrm{GSH}$ and $50 \mathrm{mg} / \mathrm{l} \mathrm{AA}$ have distinct profiles, different from those not protected and closer to the clusters of the less oxidised wines. The treatment of musts with GSH shows clear influences at the dose of $40 \mathrm{mg} / \mathrm{l}$, but for the lower dose of $20 \mathrm{mg} / \mathrm{l} \mathrm{GSH}$ in Feteasca regala wines it is difficult to identify differences compared to the wines included in the cluster of samples not treated with GSH. This finding is particularly relevant as the dose of $20 \mathrm{mg} / \mathrm{l} \mathrm{GSH}$ is the maximum allowed at present to be added in must and wines.
\end{abstract}

\section{Introduction}

The protection of wine volatiles from oxidation is one of the most desirable effects achieved by the use of the antioxidants or other compounds in winemaking or during bottling. Among the oenological permitted practices are the addition of glutathione (GSH), ascorbic acid (AA) and catechinic tannin $(\mathrm{T})$ in must or wines, as well as the bottling of the wines in the presence of carbon dioxide. For this reason, although not able to replace the sulphur dioxide in spite of many trials [7,10,11,13], these compounds have been widely used and assessed in winemaking in various combinations and doses, both for still [5,7-9,12,16,18-20] and sparkling wines [21, 22]. Taking into account the many possible combinations and reactions in wine, the effect of their application is difficult to assess by sensory analyses or by physicochemical determinations. One rapid method for evaluating the effects of these compounds on the resulted wines is the comparison of the volatile profiles of wines by using a flash gas chromatography electronic nose. This technology

\footnotetext{
a e-mail: arina.antoce@horticultura-bucuresti.ro

b e-mail: aantoce@yahoo.com
}

allows for a precise and time-efficient evaluation of clusters of samples grouped based on similar treatments [1], such as combinations of antioxidants, or common product traits, such as origin $[14,17]$ or other $[2,4]$. The technique does not directly identify the volatile compounds, but rather records non-target signals resulted from the chromatographic separation of the volatile fraction present in the sample headspace and uses them as variables (e-nose sensors) for multivariate statistical analysis.

Although the electronic nose does not tell which volatile profile is better from the viewpoint of the consumer, it can evaluate many samples in a short period of time and show if samples grouped in various clusters in accordance to the undergone treatments can be discriminated or not. If some clusters of samples cannot be discriminated by the electronic nose, most likely, from the viewpoint of the perceived volatile profile, they will not be discriminated by the consumers either. Thus, the presence of clusters which cannot be discriminated would mean that the treatments performed on the wines included in those clusters are not important enough to induce perceivable differences and may not be worth applying in the wine cellar. 


\section{Materials and methods}

The wines evaluated were obtained in normal wine cellar conditions from Feteasca regala wine grapes cultivated in the experimental field of the University of Agronomic Science and Veterinary Medicine of Bucharest, Department of Viticulture and Enology. The oenological materials used were: L-glutathione reduced (Carl Roth $\mathrm{GmbH}$, purity min. $98 \%$ for biochemistry), $\mathrm{L}(+)$-ascorbic acid (Carl Roth $\mathrm{GmbH}$, purity min 99\%, for biochemistry), catechinic tannin (Ti Premium, Enologica Vason), carbon dioxide (Buse Gaz, purity min. 99.99\%) Saccharomyces cerevisiae yeast (Premium blanc $12 \mathrm{~V}$ yeast, Enologica Vason), fermentation activator (V Starter TF, Enologica Vason). The free-run must of Feteasca regala had the following parameters: $21.6 \%$ Brix; total titratable acidity of $82.7 \mathrm{meq} / \mathrm{l}$; pH 3.33 and $135 \mathrm{mg} / \mathrm{l}$ YAN.

The experimental wine was obtained in stainless steel tanks of 501 volume, with temperature control of fermentation. For the wine variants preparations reduced glutathione (GSH) was added in the musts in doses of 0,20 and $40 \mathrm{mg} / \mathrm{l}$. The sample variants with 20 and $40 \mathrm{mg} / \mathrm{l} \mathrm{GSH}$ were prepared either without or with $50 \mathrm{mg} / \mathrm{l}$ AA added also before the onset of fermentation. In this way, after fermentation, 5 types of wines were obtained, coded in accordance to the oenological treatments of musts as G0, G20, G20A, G40 and G40A. After racking and cold stabilisation for 3 months in tanks, the variants were bottled in 0.751 volume glass containers, at this stage dividing each variant in accordance with some supplementary treatments performed during bottling, as follows: addition of 0 or $20 \mathrm{mg} / \mathrm{l}$ catechinic tannin (T00 and T20) and addition or not of carbon dioxide in the headspace of the bottle.

Usual dosages of the sulphur dioxide were maintained in the musts and wines, being corrected when necessary, so that the average of the free sulphur dioxide in wines was $26 \mathrm{mg} / \mathrm{l}$ and the total sulphur dioxide $132 \mathrm{mg} / \mathrm{l}$. Detailed wine preparation techniques and the complete results for the main wine physico-chemical parameters (measured at the moment of electronic nose assessment) are presented in another paper [3]. The coding for each wine and the treatments made are included in Table 1.

One year from the bottling time the wines were evaluated with an electronic nose working on the principle of gas chromatography (GC E-nose Heracles, Alpha MOS, France). The apparatus used is a flash GC endowed with a Tenax trap and two short chromatographic columns of $2 \mathrm{~m}$ length and $0.18 \mathrm{~mm}$ diameter - one non-polar (DB5 - 5\% diphenyl, 95\% dimethylpolysiloxane) and another of low/mid polarity (DB1701 - 14\% cyanopropylphenyl, $86 \%$ dimethylpolysiloxane) working simultaneously. The separated compounds are detected with flame ionization detectors placed at the end of each chromatographic column. Hydrogen is used both as carrier and combustion gas.

The wines from each variant are introduced in triplicate (repetitions $\mathrm{r} 1-\mathrm{r} 3$ ) in vials of $10 \mathrm{ml}$, which are filled with a volume of $4 \mathrm{ml}$ of wine sample and sealed with magnetic caps with silicone septa, specially designed for the autosampler HS 100 (Combi PAL Auto-Sampler System, CTC Analytics AG, Switzerland). The method of sample analysis involves a step of warming up the sample in the autosampler shaking oven for 10 minutes at $60^{\circ} \mathrm{C}$
Table 1. Coding and antioxidant treatments of the wine samples.

\begin{tabular}{|l|l|l|l|l|}
\hline Sample code & $\begin{array}{l}\text { Glutathione } \\
(\mathrm{mg} / \mathrm{l})\end{array}$ & $\begin{array}{l}\text { Ascorbic } \\
\text { acid } \\
(\mathrm{mg} / \mathrm{l})\end{array}$ & $\begin{array}{l}\text { Catechinic } \\
\text { tannin } \\
(\mathrm{mg} / \mathrm{l})\end{array}$ & $\begin{array}{l}\text { Carbon } \\
\text { diox- } \\
\text { ide* }\end{array}$ \\
\hline Stage of treatment & \multicolumn{2}{|c|}{ Winemaking } & \multicolumn{2}{|c|}{ Bottling } \\
\hline G00_A00_T00 & 0 & 0 & 0 & no \\
G00_A00_T00_CO2 & 0 & 0 & 0 & yes \\
G00_A00_T20 & 0 & 0 & 20 & no \\
G00_A00_T20_CO2 & 0 & 0 & 20 & yes \\
G20_A00_T00 & 20 & 0 & 0 & no \\
G20_A00_T00_CO2 & 20 & 0 & 0 & yes \\
G20_A00_T20 & 20 & 0 & 20 & no \\
G20_A00_T20_CO2 & 20 & 0 & 20 & yes \\
G20_A50_T00 & 20 & 50 & 0 & no \\
G20_A50_T00_CO2 & 20 & 50 & 0 & yes \\
G20_A50_T20 & 20 & 50 & 20 & no \\
G20_A50_T20_CO2 & 20 & 50 & 20 & yes \\
G40_A00_T00 & 40 & 0 & 0 & no \\
G40_A00_T00_CO2 & 40 & 0 & 0 & yes \\
G40_A00_T20 & 40 & 0 & 20 & no \\
G40_A00_T20_CO2 & 40 & 0 & 20 & yes \\
G40_A50_T00 & 40 & 50 & 0 & no \\
G40_A50_T00_CO2 & 40 & 50 & 0 & yes \\
G40_A50_T20 & 40 & 50 & 20 & no \\
G40_A50_T20_CO2 & 40 & 50 & 20 & yes \\
\hline
\end{tabular}

*(Bottle headspace filling).

and $500 \mathrm{rpm}$, extraction with a HS syringe of a $2.5 \mathrm{ml}$ gas sample from the head-space and injection into the GC. The chromatographic program used for the separation on both columns has the following parameters: trap temperature $40^{\circ} \mathrm{C}$, trap desorption temperature $250^{\circ} \mathrm{C}$, trap purge time $50 \mathrm{~s}$, bake-out $50 \mathrm{~s}$, initial column temperature $40^{\circ} \mathrm{C}$ with an increase rate of $5^{\circ} \mathrm{C} / \mathrm{s}$ up to $200^{\circ} \mathrm{C}$, FID temperature $220^{\circ} \mathrm{C}$, FID fuel pressure 35 psi. The aquisition time is $46 \mathrm{~s}$, with $5 \mathrm{~min}$ between 2 sample analyses. Some other details related to the method and apparatus can be found in other papers $[1,2,4]$. The data processing was done using the apparatus software, AlphaSoft V12.42.

Discriminant factor analysis (DFA) was selected as the most relevant statistical method to apply to separate the groups of samples.

To ensure that no information is lost, unless stated otherwise, for the statistical analysis all sensors (chromatographic peaks) identified by the apparatus were selected and used, irrespective of their discriminant power (Table 2).

As seen in Table 2, the sensors represent the chromatographic peaks determined by the AlphaSoft as being the most discriminant for the analysed samples and they are from both chromatographic columns (suffix 1A for the column DB5, 2A from the column DB1701).

\section{Results and discussion}

In order to compare wine samples containing various types of antioxidants, the variants were grouped in accordance with the main antioxidants used for their preparation. The variants treated with carbon dioxide were included in the clusters with similar samples not treated with $\mathrm{CO}_{2}$, as the sensory analyses on the samples showed no perceivable influence [3]. Thus, the following clusters are formed (Table 3). 
Table 2. The selection of the sensors (chromatographic peaks) for the DFA analysis.

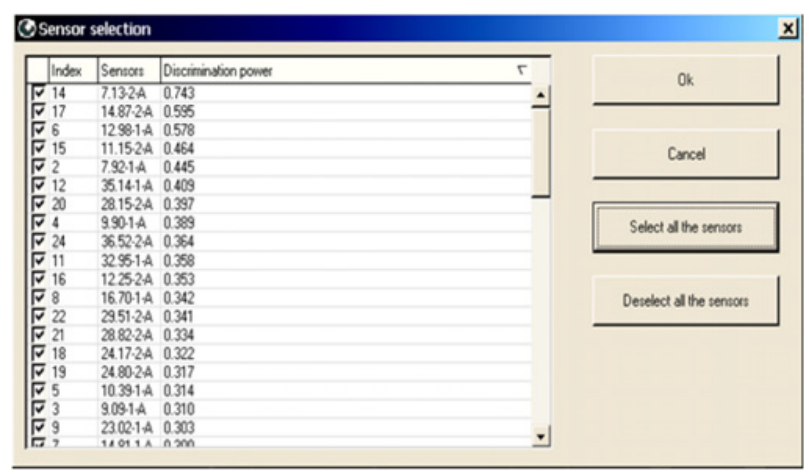

Table 3. Clusters of wines grouped in accordance with the main antioxidant treatments.

\begin{tabular}{|c|c|c|c|}
\hline $\begin{array}{l}\text { Cluster } \\
\text { name }\end{array}$ & $\begin{array}{l}\text { Sub-cluster } \\
\text { name }\end{array}$ & Sample code & $\begin{array}{c}\text { Color in } \\
\text { figures }\end{array}$ \\
\hline \multirow{4}{*}{ G0 } & \multirow{2}{*}{ G0T0 } & G00_A00_T00 (r1-r3) & Light \\
\hline & & G00_A00_T00_CO2 (r1-r3) & blue \\
\hline & \multirow{2}{*}{ G0T20 } & G00_A00_T20 (r1-r3) & Dark \\
\hline & & G00_A00_T20_CO2 (r1-r3) & blue \\
\hline \multirow{4}{*}{ G20 } & \multirow{2}{*}{ G20 } & G20_A00_T00 (r1-r3) & Light \\
\hline & & G20_A00_T00_CO2 (r1-r3) & green \\
\hline & \multirow{2}{*}{ G20T20 } & G20_A00_T20 (r1-r3) & Dark \\
\hline & & G20_A00_T20_CO2 (r1-r3) & green \\
\hline \multirow{4}{*}{$G 20 A$} & \multirow{2}{*}{ G20AT0 } & G20_A50_T00 (r1-r3) & Light \\
\hline & & G20_A50_T00_CO2 (r1-r3) & orange \\
\hline & \multirow{2}{*}{ G20AT20 } & G20_A50_T20 (r1-r3) & Dark \\
\hline & & G20_A50_T20_CO2 (r1-r3) & orange \\
\hline \multirow{4}{*}{ G40 } & \multirow{2}{*}{ G40T0 } & G40_A00_T00 (r1-r3) & Light \\
\hline & & G40_A00_T00_CO2 (r1-r3) & cyan \\
\hline & \multirow[b]{2}{*}{ G40T20 } & G40_A00_T20 (r1-r3) & Dark \\
\hline & & G40_A00_T20_CO2 (r1-r3) & cyan \\
\hline \multirow{4}{*}{ G40A } & \multirow{2}{*}{ G40AT0 } & G40_A50_T00 (r1-r3) & Light \\
\hline & & G40_A50_T00_CO2 (r1-r3) & magenta \\
\hline & \multirow{2}{*}{ G40AT20 } & G40_A50_T20 (r1-r3) & Dark \\
\hline & & G40_A50_T20_CO2 (r1-r3) & magenta \\
\hline
\end{tabular}

The clusters take into account only the presence of GSH and AA, irrespective of the tannin treatment, while the sub-clusters take also into account the presence of tannin.

\subsection{The influence of glutathione and ascorbic acid treatments}

First we tried to discriminate the volatile profiles of the wines treated with various dosages of GSH in the presence or absence of AA. The clusters were formed based on the content of GSH and AA, irrespective of the presence of tannin, as described in Table 3 - first column (clusters G0, G20, G40, G20A, and G40A).

All the chromatographic peaks were selected for the DFA analysis, having discrimination power from 0.060 to 0.709 .

As it can be seen in Fig. 1 the electronic nose discriminates the clusters of wines, and most of the variation is included in the discriminant function 1 $(87.41 \%)$.

The treatment with AA clearly influences the volatile profile of the wines, thus the electronic nose separates in

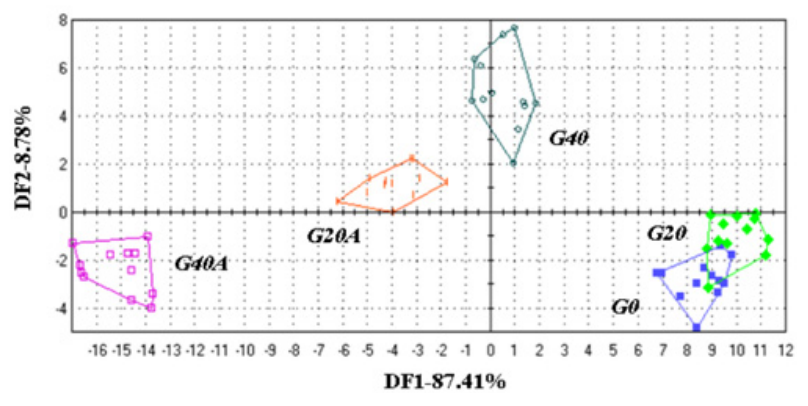

Figure 1. Discrimination of wines grouped in clusters in accordance to the glutathione and ascorbic acid treatments, irrespective of the presence of tannin. (GSH of 0, 20 and $40 \mathrm{mg} / \mathrm{l}$ (clusters G0, G20 and G40), GSH of 20 and $40 \mathrm{mg} / \mathrm{l}$ plus $50 \mathrm{mg} / \mathrm{l}$ AA (clusters G20A and G40A). Cluster colors: G0 - blue, G20 green, G40 - cyan, G20A - orange, G40A - magenta.

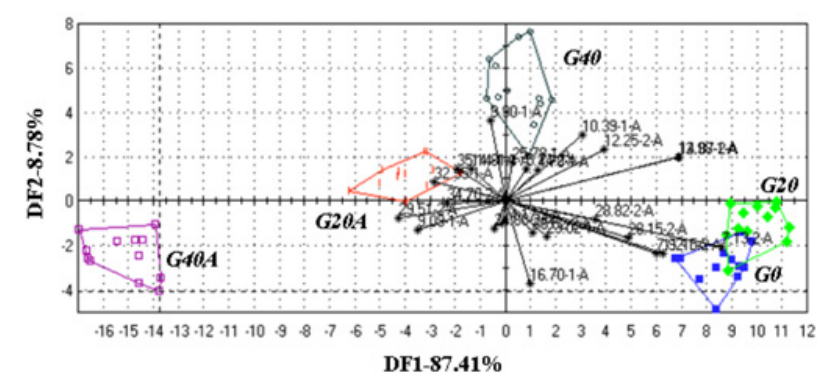

Figure 2. DFA diagram with loadings for the wine clusters discriminated in accordance to the glutathione and ascorbic acid treatments, irrespective of the presence of tannin. (GSH of 0, 20 and $40 \mathrm{mg} / \mathrm{l}$ (clusters G0, G20 and G40), GSH of 20 and $40 \mathrm{mg} / \mathrm{l}$ plus $50 \mathrm{mg} / 1 \mathrm{AA}$ (clusters G20A and G40A). Cluster colors: G0 blue, G20 - green, G40 - cyan, G20A - orange, G40A - magenta.

the right part the wines containing only GSH from the wines containing both GSH and AA, which are included in the left part of the diagram (Fig. 1).

The presence of AA reduces the number of discriminative substances (chromatographic peaks) present in the headspace of the wine sample vials, suggesting that the volatile profiles of these wines are less complex. This can be qualitatively demonstrated by the diagram in Fig. 2, where the loadings of the chromatographic peaks are also represented along with the wine clusters. Fewer and shorter loadings determine the differentiation of the clusters G20A and G40A, those that contain samples with AA along with GSH.

Interestingly, the wines treated with only $20 \mathrm{mg} / \mathrm{l}$ GSH do not appear to have significantly different volatile profiles compared to the control wines. This can be seen in both Fig. 1 and Fig. 2, where the clusters G0 and G20 overlap. Also, if we take into account the discriminant function 3, same result is obtained (Fig. 3).

This observation is important, as the dose of $20 \mathrm{mg} / \mathrm{l}$ $\mathrm{GSH}$ is the maximum allowed at present for the treatments of musts and wines in accordance to the International Organisation of Vine and Wine recommendations [15].

The fact that the electronic nose does not discriminate the samples treated with $20 \mathrm{mg} / \mathrm{l} \mathrm{GSH}$ from those not treated (control samples) means that from the viewpoint of the aromatic profile the consumer will most likely perceive no difference as well. 


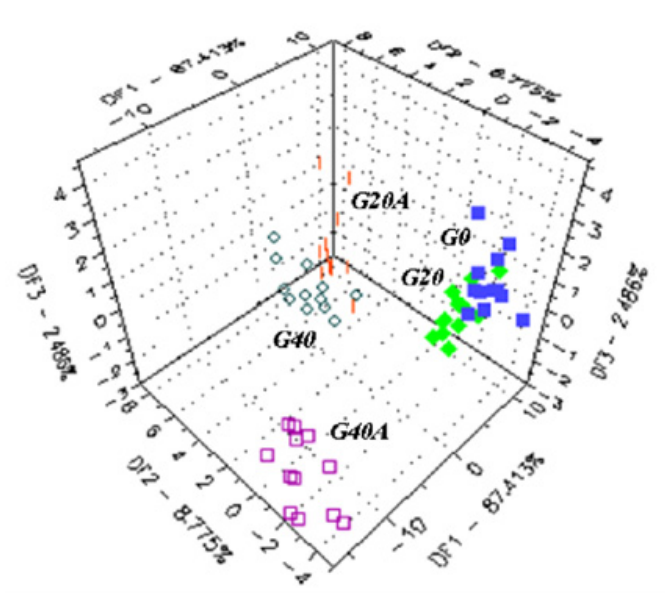

Figure 3. DFA 3D diagram for the wine clusters discriminated in accordance to the glutathione and ascorbic acid treatments, irrespective of the presence of tannin. (GSH of 0, 20 and $40 \mathrm{mg} / \mathrm{l}$ (clusters G0, G20 and G40), GSH of 20 and $40 \mathrm{mg} / \mathrm{l}$ plus $50 \mathrm{mg} / \mathrm{l}$ AA (clusters G20A and G40A.) Cluster colors: G0 - blue, G20 green, G40 - cyan, G20A - orange, G40A - magenta.

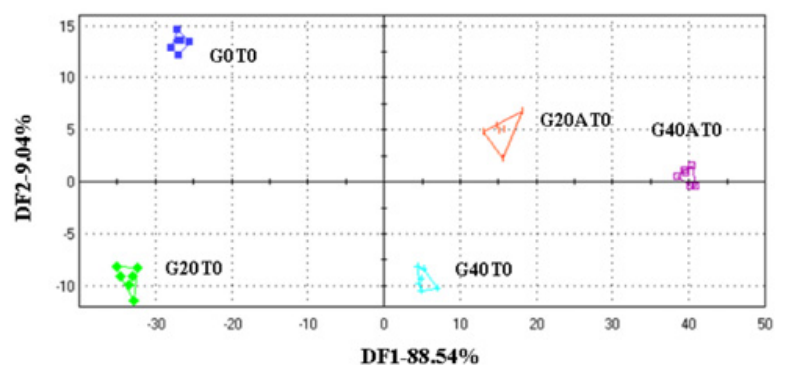

Figure 4. Discrimination of wines grouped in clusters in accordance to the glutathione and ascorbic acid in the absence of tannin. Sub-cluster colors: (G0T0 - light blue, G20T0 and G20T20 - light green, G40T0 - light cyan, G20AT0 - light orange, G40AT0 - light magenta.

This effect may, however, be due to the influence of the tannin present in some of the samples included in the analysed groups.

If we eliminate the effect of tannin, by comparing clusters of wines groups only in accordance with the GSH and AA treatments and with no tannin added, the wines containing $20 \mathrm{mg} / \mathrm{l} \mathrm{GSH}$ are also separated from the control wines. (Fig. 4), although the discrimination power of the most discriminant sensor was only 0.654 (the selected sensors ranged from 0.654 to 0.218 ).

Therefore, it is very clear that for the discrimination of the wine samples by the electronic nose and also by the consumers, the complexity of the wine matrix, and the combination of oenological treatments are important.

\subsection{The influence of tannin treatment}

To determine the influence of the treatment with tannin on the volatile profile of wines already vinified with GSH and AA the DFA analysis was performed by grouping the samples in clusters containing also tannin $(0$ or $20 \mathrm{mg} / \mathrm{l})$, as described in Table 3 second column (sub-clusters G0T0 and G0T20, G20T0 and G20T20, G40T0 and G40T20, G20AT0 and G20AT20, G40AT0 and G40AT20).

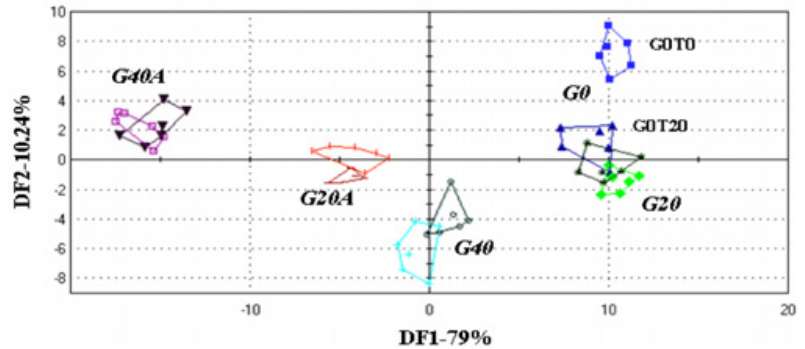

Figure 5. Discrimination of wines grouped in clusters in accordance to the glutathione, ascorbic acid and tannin treatments. GSH of 0,20 and $40 \mathrm{mg} / 1$ (clusters G0, G20 and G40), GSH of 20 and $40 \mathrm{mg} / 1$ plus $50 \mathrm{mg} / \mathrm{l} \mathrm{AA}$ (clusters G20A and G40A). Sub-cluster colors: G0T0 and G0T20 - light and dark blue, G20T0 and G20T20 - light and dark green, G40T0 and G40T20 - light and dark cyan, G20AT0 and G20AT20 - light and dark orange, G40AT0 and G40AT20 - light and dark magenta.

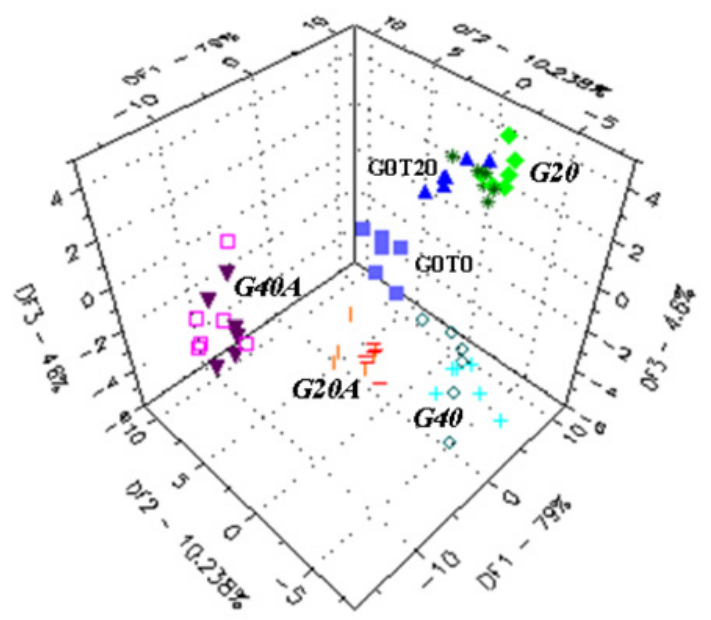

Figure 6. DFA 3D diagram for the wine clusters treated with glutathione, ascorbic acid and tannin treatments.

All the sensors were selected for analysis, with discrimination power ranging from 0.078 to 0.754 .

The results showed that the presence of $20 \mathrm{mg} / \mathrm{l}$ tannin was not important enough to have a perceivable impact on the on the wine samples, as compared to the GSH or AA treatments.

Figures 5 and 6 show that the clusters with and without tannin overlap in all groups with the exception of the control cluster (blue color) which is split in the G0T0 (light blue) and G0T20 dark blue) sub-clusters.

The fact that in the control cluster we observe a slight discrimination between samples treated with tannin and those not treated suggests that the tannin actually influences the volatile profile of the wines, but when the GSH or AA are also added, its effect is masked by the greater effect induced by these other antioxidants.

The main effect on the volatile profile of the wines is induced by the GSH and the combination of GSH and AA. This is more clearly demonstrated when only the sub-clusters containing tannin are compared (Fig. 7). The sensor selection ranged from 0.817 to 0.222 discrimination power.

In Fig. 7 to the clusters of samples treated with both GSH and AA (right) are separated from the clusters of samples treated only with GSH (left), while the dose 


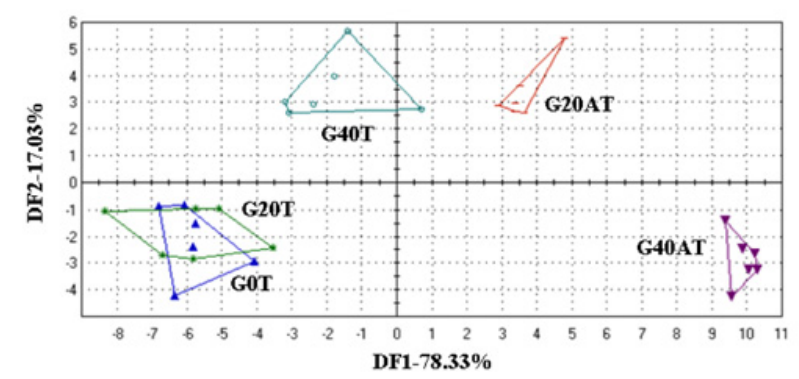

Figure 7. Discrimination of wines treated with tannin grouped in clusters in accordance to the glutathione and treatments. Subcluster colors: G0T20 - dark blue, G20T20 - dark green, G40T20 - dark cyan, G20AT20 - dark orange, and G40AT20 - dark magenta.

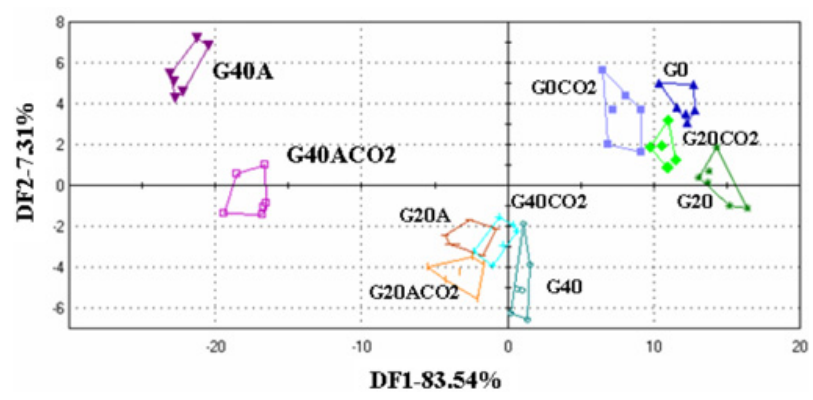

Figure 8. Discrimination of wines grouped in clusters in accordance to the glutathione, ascorbic acid and carbon dioxide treatments. GSH of 0,20 and $40 \mathrm{mg} / 1$ (clusters G0, G20 and G40), GSH of 20 and $40 \mathrm{mg} / 1$ plus $50 \mathrm{mg} / \mathrm{l} \mathrm{AA}$ (clusters G20A and G40A). Sub-cluster colors: G0CO2 and G0 - light and dark blue, G20CO2 and G20 - light and dark green, G40CO2 and G40 - light and dark cyan, G20ACO20 and G20A - light and dark orange, G40ACO2 and G40A- light and dark magenta.

of $20 \mathrm{mg} / \mathrm{l} \mathrm{GSH}$ is not sufficiently important to ensure discrimination of samples from the control wines, not treated with GSH.

The results obtained under our experimental conditions seem to indicate that at least the treatment with $20 \mathrm{mg} / \mathrm{l}$ GSH in Feteasca regala does not lead to any benefit as far as the aromatic profile is concerned. Comparable results were obtained by other authors too [18], the 20 and $40 \mathrm{mg} / \mathrm{l}$ GSH treatments of certain white wines (also containing AA from the must treatment) leading to no significant difference in sensory parameters as compared to control wines.

\subsection{The influence of carbon dioxide treatment}

Although in a previous study the sensory analysis of the samples did not show any perceivable influence of the carbon dioxide on the aroma intensity and quality of these samples [3], the discrimination by electronic nose of the groups of samples with and without carbon dioxide added during bottling was also attempted (Fig. 8). The wines were grouped in the same clusters based on the treatments of GSH and AA, irrespective of the presence of tannin, but then, each cluster was split in sub-clusters with $\mathrm{CO}_{2}$ (light colored) and without $\mathrm{CO}_{2}$ (dark colored).

After 1 year from bottling time, the addition of carbon dioxide in the bottles did not influence significantly the aroma profile. All the sub-clusters containing wines with $\mathrm{CO}_{2}$ overlapped with their corresponding sub-cluster without $\mathrm{CO}_{2}$, with the exception of the samples with both $40 \mathrm{mg} / \mathrm{l} \mathrm{GSH}$ and $50 \mathrm{mg} / \mathrm{l} \mathrm{AA}$, which, as shown in other studies too $[6,23]$ are the most prone to oxidation. Thus, we can see that after 1 year in bottle, without $\mathrm{CO}_{2}$ protection, the wines containing a larger dose of GSH and in the presence of AA (group G40A) show different profiles of the volatile substances as compared to all the other wines.

This result suggests that, in time, the effects of preservation with carbon dioxide will be more easily detectable and that the treatment is worth making.

\section{Conclusions}

The electronic nose can discriminate fast and reliably the samples of wines prepared with various oenological treatments.

Based on the statistical analysis of the discriminant factors (DFA) we were able to evaluate if the antioxidant treatments of white wines of Feteasca regala induced significant differences in the volatile profile 6 month after winemaking and 1 year after bottling.

Thus, in our study, the electronic nose helped to establish the following effects determined by the treatments with the antioxidants on Feteasca regala wines:Generally, the treatment with GSH in the must influences the volatile profile of the final wines only at doses larger than the $20 \mathrm{mg} / \mathrm{l}$ allowed at present by the OIV. The cluster of wines resulted from musts treated with $20 \mathrm{mg} / \mathrm{l} \mathrm{GSH}$ was not discriminated by the electronic nose from the cluster without GSH added. A discrimination was however possible when the effect of tannin added was removed from the analysis, by excluding from the wine sample clusters the samples with added tannin.

The addition before fermentation of $50 \mathrm{mg} / \mathrm{l} \mathrm{AA}$ in the musts treated with GSH, irrespective of the GSH dosage, reduced the complexity of the volatile profile of wines. The presence of AA in the samples determined the clear discrimination of the clusters containing wines with AA, from those without AA, irrespective of the other treatments.

The treatment with only $20 \mathrm{mg} / \mathrm{l}$ catechinic tannin during bottling was generally not important enough to induce perceivable effects on the volatile profile, in the context of addition of AA or/and GSH in the musts, which had a greater influence.

The treatment with carbon dioxide during bottling shows a promising effect in the long run. At 1 year form bottling, the wines mostly prone to oxidation (those included in the cluster of samples treated with $40 \mathrm{mg} / \mathrm{lGSH}$ and $50 \mathrm{mg} / \mathrm{l} \mathrm{AA}$ ) are split in sub-clusters of samples with and without $\mathrm{CO}_{2}$ preservation. The subcluster with $\mathrm{CO}_{2}$ is positioned closer to the samples less oxidised.

Of all the findings, the fact that the treatment of must with $20 \mathrm{mg} / \mathrm{l} \mathrm{GSH}$ in Feteasca regala wines does not induce major differences in the volatile profiles of the resulted wines from the wines included in the cluster of samples not treated with GSH is particularly relevant as the dose of $20 \mathrm{mg} / \mathrm{l} \mathrm{GSH}$ is at present the maximum allowed to be added in must and wines. 
The authors declare no financial or commercial conflicts of interest.

\section{References}

[1] Antoce Arina Oana, Namolosanu C. I., 2011. Rapid and precise discrimination of wines by means of an electronic nose based on gas-chromatography, Revista de Chimie 62(6), p. 593-595

[2] Antoce A. O., 2012. Influence of Maceration Enzyme Treatment on the Colour and Volatile Profile of Two Red Romanian Wines", Revista de Chimie 63(9), p. 859-864

[3] Antoce A. O., Cojocaru G. A., 2017. Sensory profile changes induced by the antioxidant treatments of white wines - the case of glutathione, ascorbic acid and tannin treatments on Feteasca regala wines produced in normal cellar conditions, AgroLife Scientific Journal 6(1) (sent for publication)

[4] Antoce O. A., Stroe M. V., Cojocaru G. A., 2015. Tentative application of an electronic nose to the study of the parentage of Romanian grape varieties Sarba and Alb Aromat, Agriculture and Agricultural Science Procedia, Elsevier 6, p. 110-117

[5] Bradshaw M. P., Barril C., Clark A. C., Prenzler P. D., and Scollary G. R., 2011. Ascorbic acid: A review of its chemistry and reactivity in relation to a wine environment. Critical Reviews in Food Science and Nutrition 51(6), 479-498

[6] Cojocaru G. A., Antoce O. A., 2016. Oxygen intake and color evolution in Sauvignon Blanc and Muscat Ottonel wines treated with ascorbic acid and glutathione, AgroLife Scientific Journal 5(1), pp. $44-50$

[7] Comuzzo P., Battistutta F., Vendrame M., Páez M. S., Luisi G. and Zironi R., 2015. Antioxidant properties of different products and additives in white wine. Food Chemistry 168, 107-114

[8] Danilewicz J. C., Seccombe J. T., Whelan J., 2008. Mechanism of Interaction of Polyphenols, Oxygen and Sulphur Dioxide in Model Wine and Wine. American Journal of Enology and Viticulture, 59(2), 128-136

[9] El Hosry L., Auezova L., Sakr A., Hajj-Moussa E., 2009. Browning susceptibility of white wine and antioxidant effect of glutathione. Int $\mathrm{J}$ Food Sci Technol 44, p. 2459-2463

[10] Fracassetti D., Gabrielli M., Costa C., TomasBarber F. A., Tirelli A., 2016. Characterization and suitability of polyphenols-based formulas to replace sulfur dioxide for storage of sparkling white wine, Food Control 60, p. 606-614

[11] Guerrero R. F., Cantos-Villar E., 2015. Demonstrating the efficiency of sulphur dioxide replacements in wine: A parameter review, Trends in Food Science \& Technology 42(1), p. 27-43

[12] Kritzinger E. C., Bauer F. F., du Toit W.J., 2013. Role of glutathione in winemaking: a review. J Agric Food Chem 6, p. 269-277
[13] Li H., Guo A., Wang H., 2008., Mechanisms of oxidative browning of wine, Food Chemistry 108, p. 1-13

[14] Melucci D., Bendini A., Tesini F., Barbieri S., Zappi A., Vichi S., Conte L., Toschi T.G., 2016. Rapid direct analysis to discriminate geographic origin of extra virgin olive oils by flash gas chromatography electronic nose and chemometrics, Food Chemistry 204, p. 263-273

[15] OIV, International Organisation of Vine and Wine, 2016. International code of œnological practices. OIV - 18, rue d'Aguesseau - 75008 Paris, http://www .oiv.int/public/medias/2696/ code-2016-en.pdf, retrieved on January 2017

[16] Panero L., Motta S., Petrozziello M., Guaita M. and Bosso A., 2015. Effect of SO2, reduced glutathione and ellagitannins on the shelf life of bottled white wines. European Food Research Technology 240, 345-356

[17] Peng Q., Tian R., Chen F., Li B., Gao H., 2015. Discrimination of producing area of Chinese Tongshan kaoliang spirit using electronic nose sensing characteristics combined with the chemometrics methods, Food Chemistry 178, p. 301-305

[18] Piano F., Petrozziello M., Vaudano E., Bonello F., Ferreira V., Zapata J., HernándezOrte P., 2014. Aroma compounds and sensory characteristics of Arneis Terre Alfieri DOC wines: the concentration of polyfunctional thiols and their evolution in relation to different ageing conditions, Eur Food Res Technol 239, p. 267-277

[19] Sonni F., Chinnici F., Natali N., Riponi C., 2011a. Pre-fermentative replacement of sulphur dioxide by lysozyme and oenological tannins: Effect on the formation and evolution of volatile compounds during the bottle storage of white wines, Food Chemistry

[20] Sonni F., Moore E. G., Clark A. C., Chinnici F., Riponi C. and Scollary G. R., 2011b. Impact of glutathione on the formation of methylmethine-and carboxymethine-bridged (+)-catechin dimers in a model wine system. Journal of Agricultural and Food Chemistry 59(13), 7410-7418

[21] Webber V., Dutra S. V., Spinelli F. R., Marcon A. R., Carnieli G. J. and Vanderlinde R., 2014. Effect of glutathione addition in sparkling wine. Food Chemistry 159, 391-398

[22] Webber V., Dutra S. V., Spinelli F. R., Carnieli G. J., Cardozo A. and Vanderlinde R., 2017. Effect of glutathione during bottle storage of sparkling wine, Food Chemistry 216, p. 254-259

[23] Wegmann-Herr P., Berner M., Dickescheid C., Wallbrunn C., Nickolaus P., Durner D., 2015. Influence of ascorbic acid, sulphur dioxide and glutathione on oxidation product formation in wine-like system, BIO Web of Conferences 5, 02005; http://dx.doi.org/10.1051/bioconf/ 20150502005. 129, p. 1193-1200 